\title{
Time series analysis of multi-frequency SAR backscatter and bistatic coherence in the context of flood mapping
}

Sandro Martinis(1), Christoph Rieke(2), Benjamin Fissmer(1)

(1) German Aerospace Center (DLR), German Remote Sensing Data Center (DFD)

(2) Friedrich-Schiller-University Jena

\section{Introduction}

In this study, time series analysis of multi-frequency radar backscatter $\sigma_{0}$ and bi-static coherence $y$ is accomplished to investigate the behavior of the SAR signal over several semantic classes in the context of flood mapping. The focus is on open water surfaces as well as on partially submerged vegetation such as forests and reeds at different densities. The first study area at River Saale, Germany, is covered by multi-frequency SAR data of the sensors TerraSAR-X (X-band), ALOS PALSAR (L-band) and RADARSAT-2 (C-band) and a second test site at River Wabesh/River Ohio, USA, by bi-static coherence data of the TanDEM-X mission. Flood events occurred in both times series, which allows evaluating variations of the SAR signal between flood periods and normal water level conditions.

\section{Study area and data set}

\section{AOI-1: River Saale, Germany}

The first test site is situated at Saale River, Saxony-Anhalt, Germany, which was affected by floods in January 2011 and June 2013 (fig. 1). The time-series consists of the following multi-frequency data covering the period Dec. 2009 to June 2013:

- 39 TerraSAR-X data: 37 Stripmap (HH), 2 ScanSAR (HH)

- 7 ALOS PALSAR data: 3 FBS (HH), 4 FBD (HHNV)

1 RADARSAT-2 data: 1 Fine $(\mathrm{HH})$
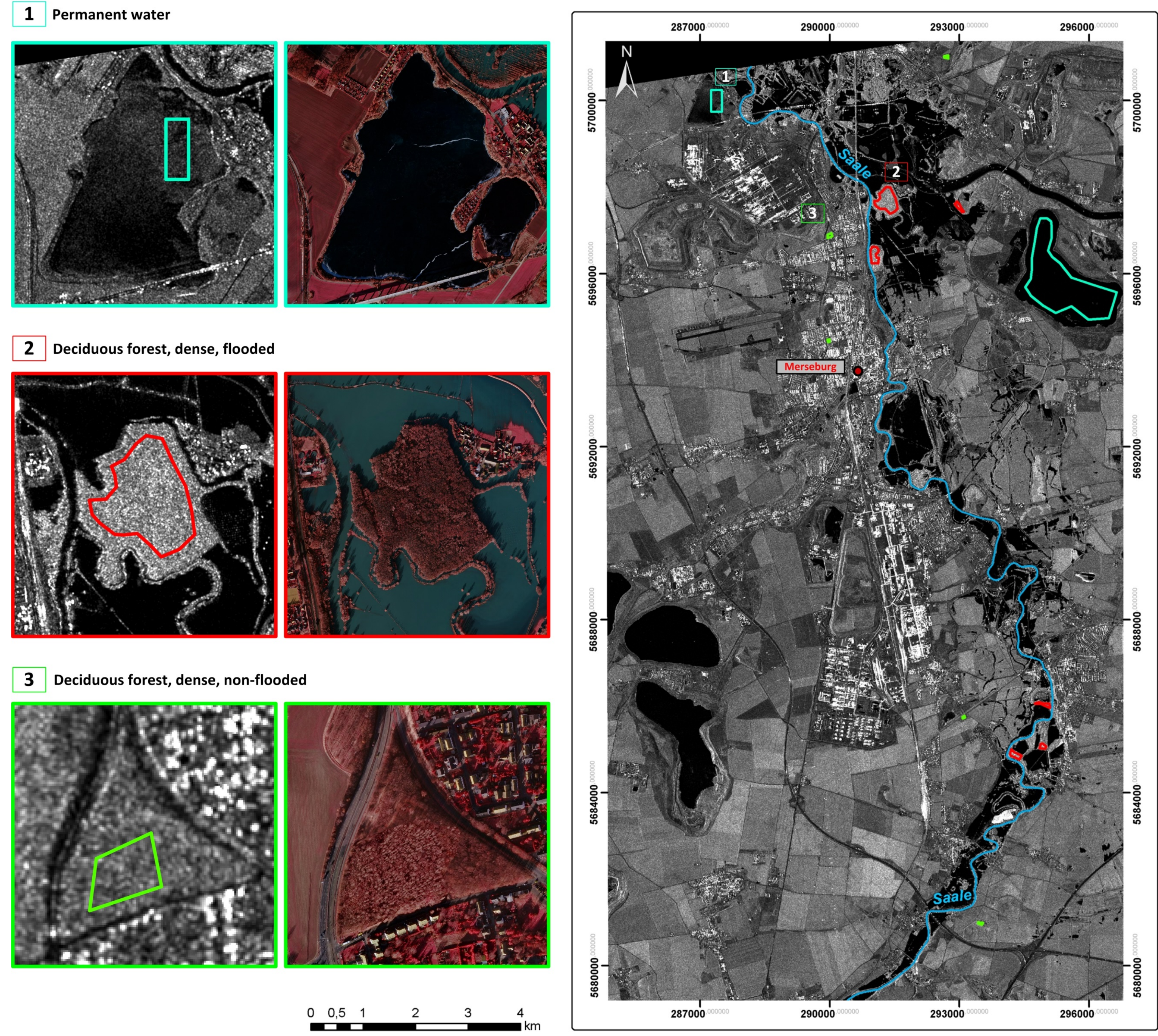

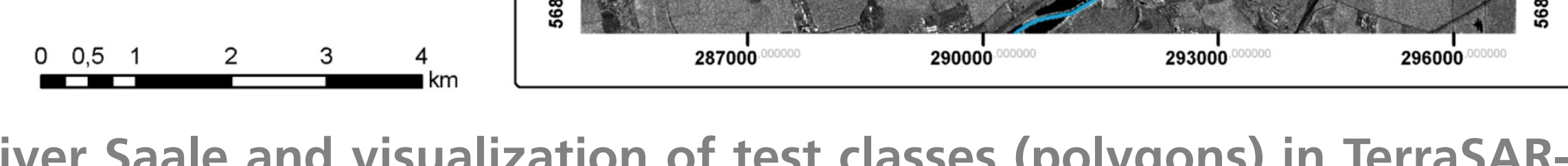
Fig. 1: Study area at River Saale and visualization of test classes (polygons) in Terr
data (17 Jan. 2011, @ DLR 2014) and aerial photographs (17 Jan. 2011, @ LHW 2011).

\section{AOI-2: Wabash River, USA}

The second test site is located at lower Wabash River, USA (fig. 2). The lowlands along the river are characterized by farmland and deciduous forests (tulip trees, maple, cottonwood, and shrubs). The time-series consists of the following data covering the time interval November 2011 and August 2014:

- 27 Co-registered single look slant range complex (CoSSC) data of the single-pass across-track SAR interferometry mission TanDEM-X: Stripmap (HH)
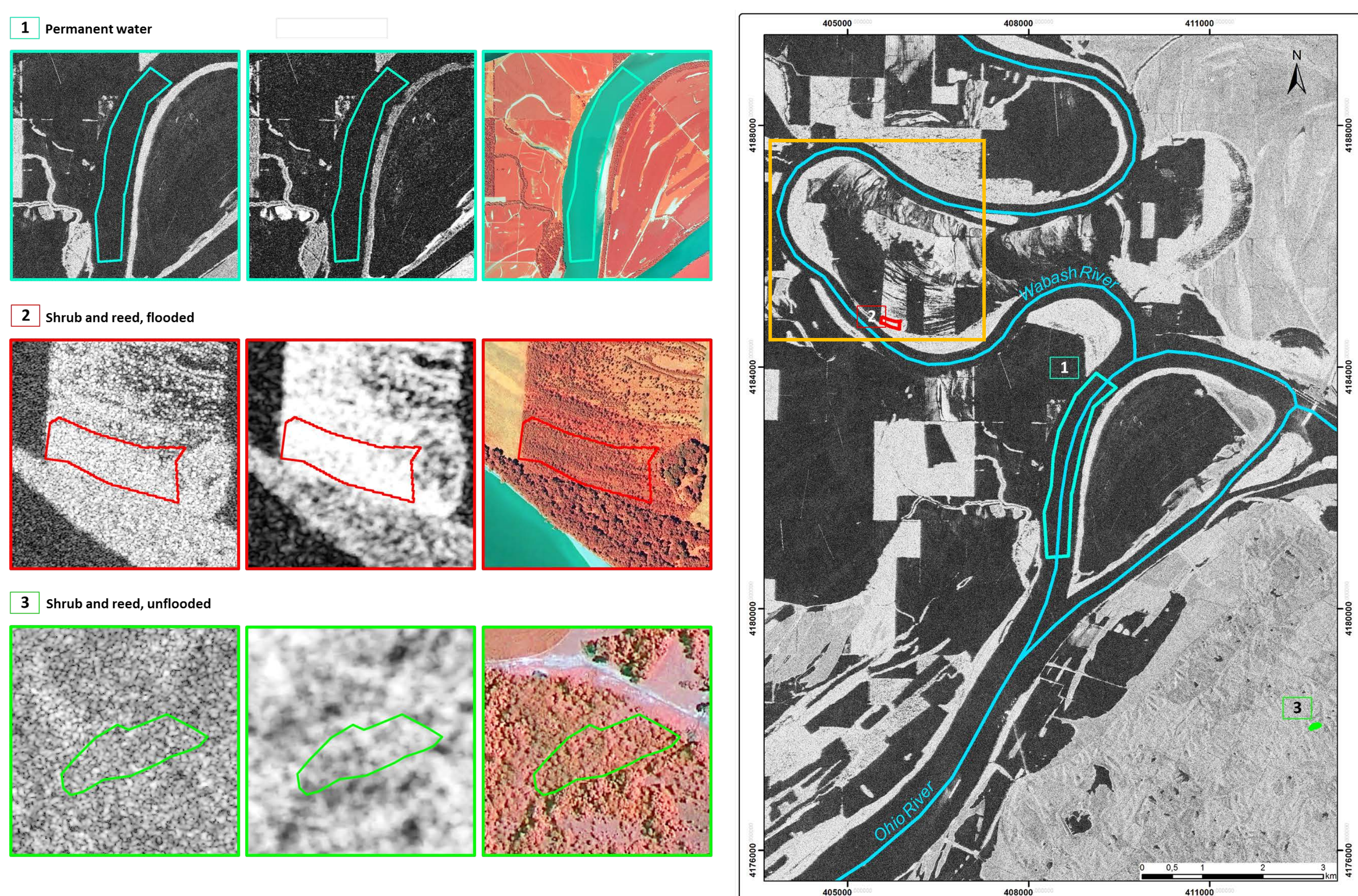

Fig. 2: Study area at River Wabash and visualization of test classes in data of the TanDEMX mission (2011-12-11, ( ) DLR 2014); left column: SAR amplitude; mid column: bistatic coherence; right column: aerial photographs (2011-08-12, 2010-06-23, ๑ USDA-FSA-APFO).

\section{Results and discussion}

The analysis of the time series for both AOls (see fig. 3, 4) was performed for 3 test classes, respectively, based on manually digitized homogeneous polygons:

- AOI-1-1: permanent water bodies

- AOI-1-2: occasionally flood affected dense deciduous forest; height: $20-25 \mathrm{~m}$

- AOl-1-3: perennial non-flood affected dense deciduous forest; height: 20-25m

- AOI-2-1: permanent water bodies

- AOI-2-2: occasionally flood affected deciduous reeds and bushes

- AOI-2-3: perennial flood non-flood affected reeds and bushes

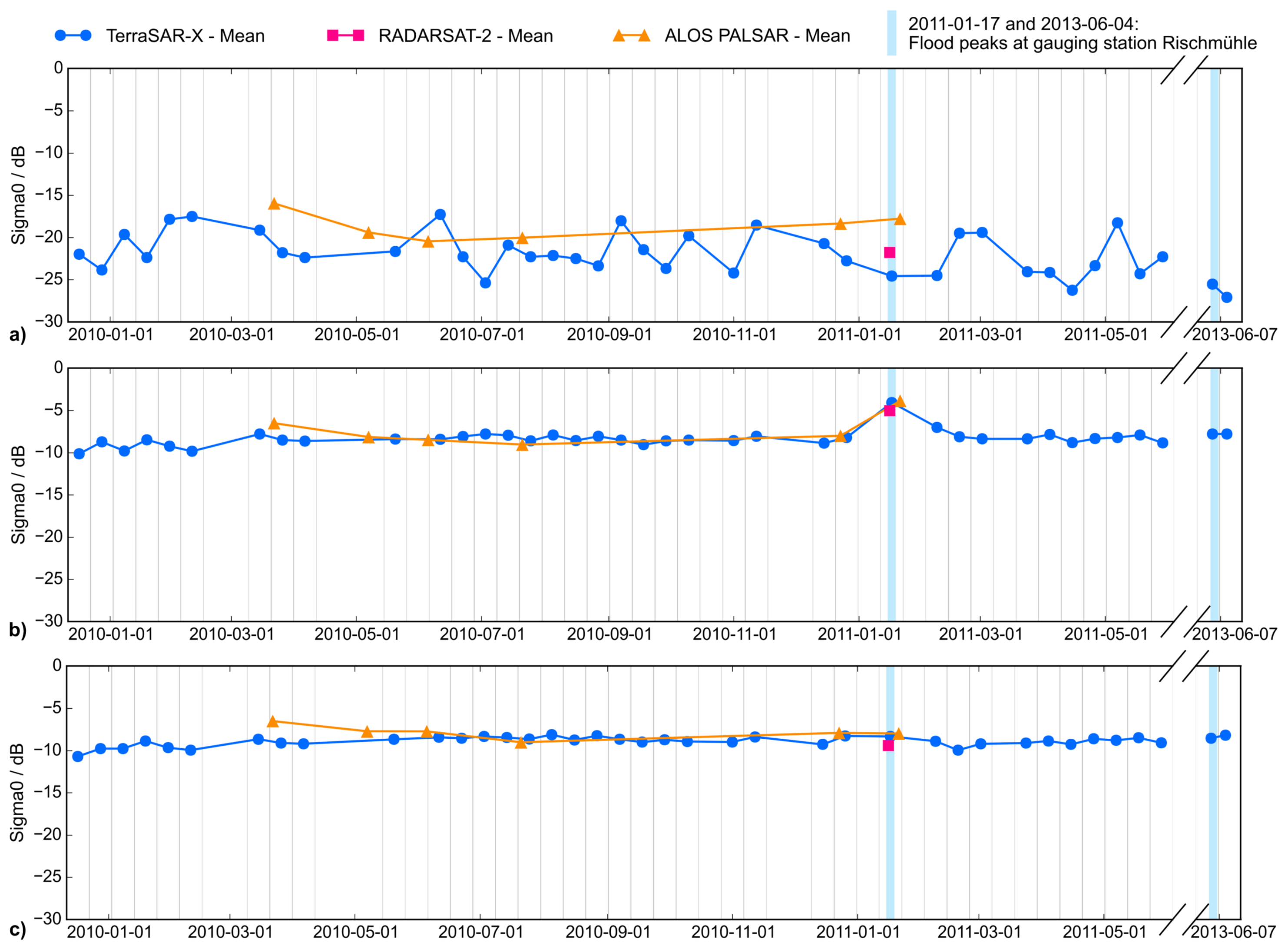

Fig. 3: Time course of mean $\sigma_{0}(\mathrm{~dB})$ for AOI 1 for a) class AOI-1-1 (permanent water), b) AOI-1-2 (deciduous forest, flooded), and c) AOI-1-3 (deciduous bushes, non-flooded).

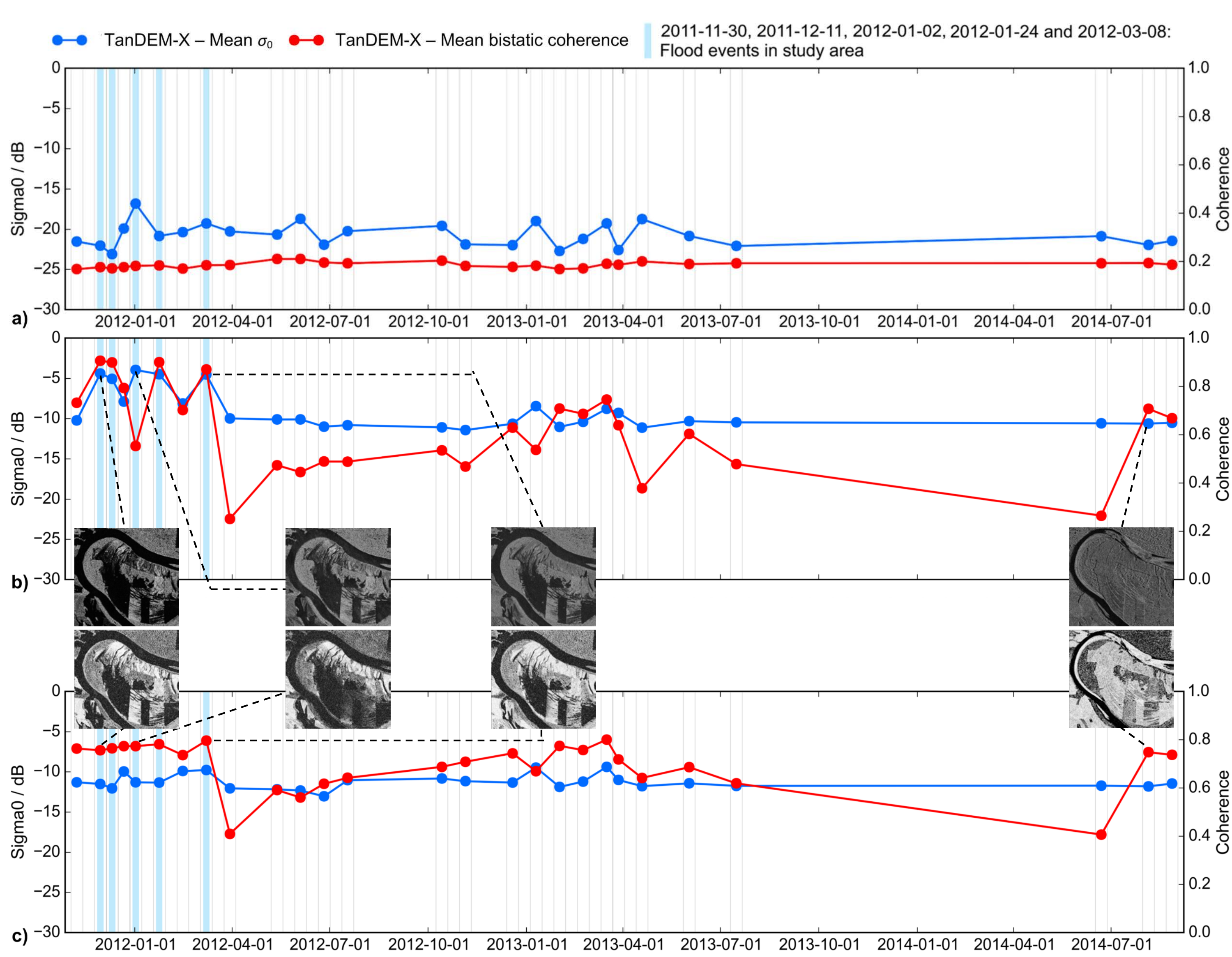

Fig. 4: Time course and selected chips (see fig. 2) of $\sigma_{0}$ and bistatic coherence for AOI 2 for a) class AOI-2-1 (permanent water), b) AOI-2-2 (reeds/bushes, flooded), and c) AOI-2-3 (reeds/bushes, non-flooded).

The main findings of the SAR time series analysis are the following:

- Permanent water (AOI-1-1, AOl-2-1) is showing strong fluctuations of $\sigma_{0}$ in $X$ band $(\Delta 10.0 \mathrm{~dB}$ and $\Delta 6.3 \mathrm{~dB})$. In L-band lower changes of $\sigma_{0}(\sim \Delta .5 \mathrm{~dB})$ appea $\rightarrow$ thresholds of $\sigma_{0}$ for water detection have to be set individually for each scene, especially for $X$-band data, e.g. using automatic thresholding.

- Bistatic coherence $y$ for class AOl-2-1 shows very low fluctuations $(\Delta 0.04)$ due to a low sensitivity to water roughness conditions. It can therefore be well used in synergy with backscatter for optimized detection of open water

- Outside the flooding, AOI-1-2 and AOI-1-3 show high conformity in $\mathrm{X}_{-}, \mathrm{C}_{-}$, and L-band. During the flooding in 2011, AOI-1-2 shows a similar backscatter in X- ($4.06 \mathrm{~dB}), \mathrm{C}-(-5.02 \mathrm{~dB})$, and $\mathrm{L}-$ band $(-3.87 \mathrm{~dB})$. These values differ clearly from the time course mean in $X-(-8.48 \mathrm{~dB})$ and L-band $(-8.10 \mathrm{~dB})$ during non-flood conditions

- Class AOl-2-2 shows an increase in $\sigma_{0}$ during flooding (mean $\sigma_{0}$ of $-4.62 \mathrm{~dB}$ vs. the non-flooded time course mean of $-10.14 \mathrm{~dB}$ ). Increasing values of $y$ can be considered as an indicator for floods: The mean $y$ of partially submerged vegetation is 0.89 , the mean of $y$ during non-flooded conditions only 0.56 .

- Perennial non-water covered areas of reeds and bushes (class AOI-2-3) show no significant variance of $y$ in the frequently flood affected period from 2011-11-30 to $2012-03-08$ in AOI-2-2

\section{Conclusion}

- There is a great potential in detecting flooding beneath vegetation in all wavelengths, even in X-band for sparse vegetation or leaf-off forests.

Due to the low sensibility of bistatic coherence to water surface roughness and its sensibility to standing water beneath vegetation it can be synergistically used with amplitude data for optimized detection of flooding. 